\title{
NAS ONDAS DO RÁDIO: ESTUDO SOBRE A RÁDIO MUNDIAL
}

\author{
ON THE WAVES OF THE RADIO: \\ STUDY ON RADIO MUNDIAL \\ EN LAS ONDAS DE RADIO: \\ ESTUDIO DE RADIO MUNDIAL
}

\author{
José Eugenio de Oliveira Menezes \\ Doutor, Faculdade Cásper Líbero \\ jeomenezes@casperlibero.edu.br \\ Monica Martinez \\ Doutora, Universidade de Sorocaba \\ monica.martinez@prof.uniso.br
}

\section{Resumo}

A Rádio Mundial, criada em 1993 como parte do grupo CBS, que inclui a Tupi e a Kiss, expressa hoje uma programação plural, feita por 164 comunicadores, indivíduos ou instituições que locam um ou mais programas de 25 minutos. Este conjunto provê um cenário sonoro com visões multifacetadas de mundo, que mesclam de conteúdos primevos (como os programas a respeito do tarô) a contemporâneos, estes em grande parte ancorados em conceitos das neurociências e da física quântica, entre outros. Este estudo qualitativo concentrou-se na faixa horária das $7 \mathrm{~h} 30$ às $8 \mathrm{~h}$, na semana de 24 a 30 de junho de 2013 . O resultado é de fato um mix radiofônico amplo que, ao vincular simbolicamente os protagonistas, incluiu de talk shows jornalísticos, numa perspectiva do jornalismo aprofundado e compreensivo, a programas com propostas de saúde e qualidade de vida.

Palavras-chave: Ecologia da comunicação. Cultura do ouvir. Jornalismo literário.

\begin{abstract}
Radio Mundial was established in 1993 as part of CBS group, which includes Tupi and Kiss radio stations. Today it broadcasts a unique programming made by 164 communicators individuals or institutions who rent one or more of the 25 minutes time slot. This set provides a multi-faceted vision of the world sound scenery, which mixes traditional content (as programs about Tarot) and contemporary content, these ones largely grounded on neuroscience and quantum physics concepts. This qualitative study was focused on the time slot from 7:30 am to 8 am (prime time) during the week of 24 to 30 June 2013. The result suggests a broad radio mix programming that symbolically links the protagonists in a context of talk shows and programs about health and quality of life, among others.
\end{abstract}

Esta obra está licenciada sob uma Licença Creative Commons. 
Keywords: Communication ecology. Culture of listening. Literary journalism.

\section{Resumen}

Radio Mundial fue establecido en 1993 como parte del grupo CBS, que incluye estaciones de radio Kiss y Tupi. Hoy esta radio difunde una programación única hecha por 164 comunicadores - personas o instituciones que alquilan una o más de los programas de 25 minutos. Este conjunto ofrece una visión multifacética de la escenografía del mundo sonoro que mezcla contenidos tradicionales (como los programas sobre Tarot) y el contenido contemporáneo, estos en gran medida basados en los conceptos de la neurociencia y la física cuántica. Este estudio cualitativo se centró en el horario de 7:30 a 8:00 durante la semana del Junio 24 al 30, 2013. El resultado sugiere una programación de radio que simbólicamente une a los protagonistas en un contexto de programas de entrevistas y programas sobre la salud y calidad de vida, entre otros.

Palabras clave: Ecología de comunicación. Cultura de la escucha. Periodismo literario.

\section{INTRODUÇÃO}

O rádio, como já observava o dramaturgo alemão Bertold Brecht (1898-1956), é um meio com potencialidades democráticas e plurais por excelência (BRECHT, 2005). Esta premissa se aplica às emissoras de rádio desde sua origem. Do ponto de vista histórico, pode-se dizer que uma das pioneiras foi a Rádio Sociedade, do Rio de Janeiro, que mais tarde viria a se chamar Rádio Mundial. Não é desta Mundial, porém, que trata este trabalho. Mas de uma rádio bem mais jovem. Este ano, 2013, a emissora completa vinte anos de atividade, agora com grade bastante diversificada. Contudo, quando começou, em abril de 1993, ainda na frequência AM (RÁDIO MUNDIAL, 2013), apresentava uma programação mais tradicional, sobretudo musical e informativa.

Ainda assim, naquela fase inicial, pode-se observar, em um dos programas, o embrião de uma rádio que, duas décadas depois, se configuraria num fenômeno midiático único no cenário nacional. Trata-se do programa Étnica, que tinha como objetivo divulgar as músicas, os costumes e as culturas de diversos países, muitas delas que ao longo dos últimos cinco séculos - e em particular a partir do século XIX - formaram as bases do povo brasileiro, como a portuguesa, francesa, alemã, armênia, judaica e italiana, entre outras. Exibido nos finais de semana, este programa foi responsável pelo nome da emissora: Mundial (RÁDIO MUNDIAL, 2013).

Algum tempo depois, a Rádio Mundial volta-se para um segmento que, na época, poderia ser classificado como de esoterismo e autoajuda. Outra mudança significativa é que 
a grade da emissora, desde então, passa a ser feita por comunicadores, isto é, por indivíduos ou instituições que locam os espaços dos programas, em geral de 25 minutos.

Em fevereiro de 1995, a Rádio Mundial muda sua sede da Rua da Consolação para a Avenida Paulista, 2.200, no bairro Cerqueira César, na capital paulista. Assume outra frequência, com 100.000 watts de potência, a $1150 \mathrm{kHz}$. Em outubro de 1999, a programação da Rádio Mundial passa a ser transmitida em FM em 95,7 MHz. A audiência, então formada pelas denominadas classes C, D e E, acompanha a migração para a FM, incorporando mais ouvintes das classes AB. Em março de 2001 a Rádio Mundial voltou a ser ofertada em AM, agora na frequência $660 \mathrm{kHz}$. Hoje as duas ofertas são concomitantes - AM em 660 kHz e FM em 95,7 MHz (RÁDIO MUNDIAL, 2013).

A Rádio Mundial faz parte do Grupo CBS, que inclui outras emissoras, como a Kiss (programação focada no rock) e a Tupi (música sertaneja). A direção geral é feita por Luci Rothschild de Abreu, uma das 19 pessoas com nomes listados no expediente da emissora, que inclui de sonoplastas a locutores e pessoal administrativo. Ela é esposa de Paulo Masci de Abreu, o proprietário do Grupo CBS - Comunicações Brasil Sat.

Uma das características desta emissora é sua abertura para a diversidade sonoro/simbólica, o que na perspectiva da Ecologia da Comunicação (MENEZES, 2009; 2012) poderíamos compreender como um processo de comunicação/cultura que se esparrama pelas porosidades entre corpos e universos simbólicos dos protagonistas ouvintes e locutores - e os equipamentos eletrônicos da emissora em AM, FM ou na internet. No âmbito do Jornalismo Literário (LIMA, 2009), estariam presentes as raízes profundas do pensamento contemporâneo (MARTINEZ, 2008; MENEZES e MARTINEZ, 2011). Os programas, com 25 minutos de duração, refletem a combinação de visões e práticas que permitem ao ser humano cultivar o sonho de que pode viver mais e melhor.

De um lado, alguns programas oferecem conteúdo endossado pela mentalidade científica predominante, com professores e doutores formados por instituições de prestígio falando de assuntos concretos, como modernos tratamentos de implante dentário. No outro lado, há alguns programas que poderiam ser considerados "de raiz", no sentido de terem sua origem em práticas tradicionais, como a leitura de tarô ou o candomblé, por exemplo. Entre estes dois polos, contudo, talvez esteja a programação que represente o coração da emissora: a mais eclética combinação de múltiplas práticas que permeiam a cultura e o imaginário (DURAND, 2012) brasileiro contemporâneo, em sua fantástica capacidade de mesclar diferentes tradições. 
Neste modelo de rádio comercial, a publicidade assume uma faceta diferenciada do conjunto dos meios de comunicação. Os cinco minutos que intercalam cada programa raramente são empregados para divulgar marcas e instituições alheias. Ao contrário. Em geral, eles eventualmente divulgam alguma iniciativa da própria rádio (como campanhas para arrecadação de alimentos para um centro de animais abandonados) ou, mais comumente, fazem chamadas para o próprio programa. Isto porque a maior parte dos recursos necessários para a locação do espaço midiático provém do próprio comunicador ou da instituição que ele (a) representa. Tanto que apenas alguns programas possuem anunciantes, na maioria dos casos relacionados ao conteúdo, como farmácias de manipulação em programas sobre medicina oriental. $O$ uso de testemuniais ou de merchandising, no entanto, não é raro, com os comunicadores divulgando produtos que empregaram "com sucesso" devido a alguma finalidade particular, como shakes para emagrecimento. Os comunicadores também usam os seus espaços para divulgar outros produtos midiáticos nos quais têm participação, informar a respeito da comercialização de espaço em sites próprios ou compartilhar entrevistas que deram para outros programas, em geral eletrônicos, na televisão ou na internet.

Segundo dados do departamento comercial da rádio, o preço do espaço para um programa semanal varia de acordo com o horário, partindo de $\mathrm{R} \$ 1.300$ por mês para o horário das 5 h até $\mathrm{R} \$ 3.868$ para o período mais disputado, o matutino, que compreende das $7 \mathrm{~h}$ às $12 \mathrm{~h}$. Estes números são referentes a julho de 2013, sendo que em agosto a tabela sofreria um aumento relativo ao IPCA, o índice nacional de preços ao consumidor amplo, o que resultaria em um ajuste de $6.5 \%$. Do ponto de vista de audiência, a emissora divulga que conta com uma média de 32 mil ouvintes por minuto.

\section{UMA PROGRAMAÇÃO SUI GENERIS}

Esta pesquisa qualitativa tem como objetivo analisar a programação da Rádio Mundial. Para isto, foi selecionada, de forma aleatória, a última semana de junho de 2013, compreendendo os dias entre 24 (segunda) e 30 de junho (domingo). Esta opção se fez levando em conta a atualidade da programação. Do ponto de vista de horário, optou-se pelo período matutino (das $7 \mathrm{~h}$ às $12 \mathrm{~h}$ ), aquele que conta com mais ouvintes. Deste período, foi selecionado o horário das $7 \mathrm{~h} 30$, um momento relevante de escuta, em particular nos dias úteis na cidade de São Paulo, uma vez que muitos ouvintes estão se deslocando para seu trabalho, ouvindo a emissora pelo rádio dos automóveis ou pelas mídias móveis. A partir desta moldura, os sete programas escolhidos para análise foram: 
Tabela 1 - Programação da Rádio Mundial no horário das 7h30 no período de 24 a 30 de junho de 2013:

\begin{tabular}{|c|c|c|c|c|c|c|}
\hline $\begin{array}{c}\text { A } \\
\text { Segunda } \\
24 / 6\end{array}$ & $\begin{array}{c}\text { B } \\
\text { Terça } \\
25 / 6\end{array}$ & $\begin{array}{c}\text { C } \\
\text { Quarta } \\
26 / 6\end{array}$ & $\begin{array}{c}\text { D } \\
\text { Quinta } \\
27 / 6\end{array}$ & $\begin{array}{c}\text { E } \\
\text { Sexta } \\
28 / 6\end{array}$ & $\begin{array}{c}\text { F } \\
\text { Sábado } \\
29 / 6\end{array}$ & $\begin{array}{c}G \\
\text { Domingo } \\
30 / 6\end{array}$ \\
\hline $\begin{array}{l}\text { Nas } \\
\text { Ondas da } \\
\text { Evolução } \\
\text { Pessoal }\end{array}$ & $\begin{array}{l}\text { Caminho } \\
\text { Profundo }\end{array}$ & $\begin{array}{l}\text { Falando } \\
\text { com o } \\
\text { doutor }\end{array}$ & $\begin{array}{l}\mathrm{O} \\
\text { Encontro }\end{array}$ & Seja Sol $^{1}$ & $\begin{array}{l}\text { Mundial e } \\
\text { Você }\end{array}$ & $\begin{array}{l}\text { A } \\
\text { Caminho } \\
\text { da Luz }\end{array}$ \\
\hline $\begin{array}{l}\text { Plínio de } \\
\text { Souza }\end{array}$ & $\begin{array}{l}\text { Edicélio } \\
\text { Bispo }\end{array}$ & $\begin{array}{l}\text { Geraldo } \\
\text { Paglia }\end{array}$ & $\begin{array}{l}\text { Luiz Mota } \\
\text { e Simone } \\
\text { Arrojo }\end{array}$ & Stélio Sol & $\begin{array}{l}\text { Samira } \\
\text { Chahine }\end{array}$ & $\begin{array}{l}\text { Sérgio } \\
\text { Miranda }\end{array}$ \\
\hline
\end{tabular}

Fonte: Dados retirados do Site da Rádio Mundial em julho de 2013.

Como o áudio do programa de domingo não estava disponível, ele não foi incluído para fins desta pesquisa. Ao todo, portanto, foram selecionados seis programas, totalizando cerca de 150 minutos ou duas horas e trinta minutos de programação.

\subsection{Os comunicadores}

Salvo expresso em contrário, o texto a seguir foi elaborado a partir do perfil dos comunicadores fornecido no próprio site da emissora. São eles, em ordem alfabética:

\subsubsection{Edicélio Bispo}

Nascido em Minas Gerais em 1948, mora em São Paulo desde 1949. Casado, pai de três moças, aos 11 anos começou a se interessar pela hipnose e pelos mistérios do inconsciente. É administrador de empresas pela PUC/SP. Durante a graduação começou sua formação transdisciplinar, cursando créditos em outras disciplinas, como Psicologia, Sociologia e Direito. Seu currículo revela a tendência autodidata em uma multiplicidade de áreas, como "Psicanálise, Psicologia Cognitiva, Programação Neurolinguística, E.M. D. R, Dianética, Bioenergética, Somatic Experience, Life Coaching, Mind Coaching, Hipnose Clínica e Regressão Clínica com treinamentos credenciados no Brasil e Exterior desde 1978”. O seu programa Caminho Profundo - Sem psicanálise nem medicamentos é

\footnotetext{
${ }^{1}$ O Audiocast do programa do dia 28de junho não estava disponível no site da emissora, tendo sido substituido, para fins desta pesquisa, pelo programa do dia 29 de junho.

${ }^{2}$ Embora não conste na grade da programação, o horário das 7 h30 é relativo ao programa A Caminho da Luz, com o comunicador Sérgio Miranda que, além de apresentador da Rádio Mundial, é diretor presidente do Núcleo Espírita Cristão e diretor conselheiro do Hospital Espírita Fabiano de Cristo, conforme informações disponíveis em: www.viladefabiano.org.br.
} 
transmitido semanalmente, às terças-feiras, das $7 \mathrm{~h} 30$ às $8 \mathrm{~h}$. Fundador e Presidente da Escola Paulista de Regressão e Hipnose desde 1984, é criador da metodologia "Caminho Profundo - sem Psicanálise nem Medicamentos” e fundador da Clinica DrHipnose em 1995. Conhecido como "Dr. Hipnose" e por associação como "Dr. Bispo", tem hoje uma marca própria, a "DrBispo-DrHipnose".

\subsubsection{Geraldo Paglia}

Paulistano da zona Norte e formado em Odontologia, é especialista em Implantodontia e em Cirurgia Buco-Maxilo-Facial, sendo também mestre em Periodontia. O seu programa Falando com o Doutor é levado ao ar duas vezes por semana (segundas-feiras das 20h30 às 21 h30 e quartas-feiras, das 7h30 às 8h). Há 25 anos dirige a Clínica Odontológica Paglia, conforme informações disponíveis em: www.clinicapaglia.com.br. Situada em Santama, reúne nove profissionais em seis salas de atendimento e centro cirúrgico. Coordenador de saúde do projeto Norte Forte, de fomento à saúde na Zona Norte de São Paulo.

\subsubsection{Luiz Mota e Simone Arrojo}

Luiz Mota é administrador de empresas com pós-graduação em Planejamento. Ministrou a disciplina de Metodologia do Trabalho Científico em diversas faculdades. O programa $O$ Encontro é levado ao ar às quintas-feiras, das $7 \mathrm{~h} 30$ às $8 \mathrm{~h}$. O carro-chefe de Luiz Mota é o tarô. Ministra cursos na Universidade do Tarot, conforme informações disponíveis em www.universidadedotarot.com.br, bem como vivências junto à natureza em seu sítio, localizado em Ribeirão Pires, São Paulo.

Simone Arrojo. A comunicadora também realiza o programa Virando a Página (segundas, quartas, quintas e sextas-feiras das $11 \mathrm{~h} 30$ às 12h). Graduada em Letras (Português/Inglês), tem pós-graduação em Marketing (ESPM) e em Administração de Eventos (www.simonearrojo.com.br). Tem formação em Constelação Familiar (técnica idealizada pelo filósofo, teólogo e psicoterapeuta alemão Bert Hellinger) e Neurolinguística, bem como cursos na área de Terapias Emocionais feitos nos Estados Unidos, Canadá, Escócia e Alemanha. Trabalha com Constelação Familiar em Grupo todas às terças e quintas-feiras. Faz atendimentos individuais com Constelação Familiar. Leva grupos para lugares sagrados de vários países para trabalhos terapêuticos.

\subsubsection{Plínio de Souza}


Bacharel em Psicologia e idealizador da consultoria Ápice Metafórum (www.apicedesenvolve.com.br). Tem vários cursos internacionais, sendo coach executivo pelo European Coaching Association (ECA), pelo International Association of CoachingInstitutes (ICI) e pela Corporate Coach U, entre outros. É também trainer em Programação Neurolinguística - PNL pela International Association of NLP (Alemanha) e Society of NLP (EUA). Na área de Constelações Sistêmicas, é certificado pelo Instituto de Filosofia Prática da Alemanha e constelador treinado por Bert Hellinger. Além das segundas-feiras, das 7h30 às 8h, Nas Ondas da Evolução Pessoal vai ao ar as terças (das 11h30 às $12 \mathrm{~h}$ e das 18h30 às 19h). O comunicador também realiza o programa Saúde Financeira às terças (7h às $7 \mathrm{~h} 30$ e $11 \mathrm{~h}$ às $11 \mathrm{~h} 30)$, sextas (8h30 às 9h) e aos sábados (16h30 às 17h). Sua empresa, a Ápice, conta com oito coachers, além de quatro pessoas na parte administrativa, sendo uma estagiária de psicologia.

\subsubsection{Samira Chahine}

Formada em Comunicação Social, habilitação em Jornalismo, pela FIAM (Faculdades Integradas Alcântara Machado, atual Centro Universitário FIAMFAAM), tem pósgraduação em nível de lato sensu em Jornalismo Especializado em Política, Economia e Cultura pela FMU (Faculdades Metropolitanas Unidas). Apresenta o programa Mundial e Você aos sábados, das $7 \mathrm{~h}$ às $8 \mathrm{~h}$. Atua como jornalista na Rádio Mundial desde 2000, onde também é responsável pelo Jornal da Boa Notícia.

\subsubsection{Stélio Sol}

Stélio Sol é o apelido de Stélio Golla Cristóvão, nascido em nove de julho de 1964, na cidade de Presidente Prudente, estado de São Paulo. É casado e pai de duas filhas. Engenheiro naval de formação (Escola Politécnica da Universidade de São Paulo - USP), se define como ativista socioambiental e apaixonado pela área de desenvolvimento pessoal. De 2007 a 2011, apresentou na rádio Mundial o programa Desafios do Aquecimento Global, sobre educação ambiental. Em 2011, passou a apresentar o programa atual, voltado para a "sustentabilidade pessoal, que busca capacitar as pessoas através de conhecimentos e técnicas que as tornem criadoras intencionais de suas próprias realidades". Além das sextasfeiras (7h30 às $8 \mathrm{~h}$ ), o programa Seja Sol-ajudando a construir novas realidades vai ao ar às segundas (8h30 às 9h), terças (18h às $18 \mathrm{~h} 30)$, quartas (12h às $12 \mathrm{~h} 30)$ e sábados (12h às

12h30). É proprietário da Brasil Sol Empreendimentos Sustentáveis Ltda., organização que pretende contribuir na promoção do "empreendedorismo sustentável e do desenvolvimento 
pessoal", de acordo com informações disponíveis no site http://www.loteamentosol.com.br/caminhodeabrolhos.

\subsection{Análise dos programas}

\subsubsection{Nas Ondas da Evolução Pessoal (24’35)}

O programa do psicólogo Plínio de Souza é fundamentado na "programação neurolinguística, no coaching integrativo sistêmico, na constelação familiar, tecnologias modernas avançadas para mudanças comportamentais e emocionais breve". Cada programa tem um foco temático. No dia 24/6 o foco foi sobre crise e resistência. Plínio é um orador inspirado, que tece seus argumentos com desenvoltura. $\mathrm{O}$ conceito básico deste programa em particular é o de crise como predecessora de processos de mudança. "O novo traz o medo" (...), "mas mudar faz parte da vida". Neste discurso, não há como não lidar com a crise: "Se você empurra com a barriga está atrasando a sua evolução, da sua equipe, da sua família, do país - não adianta querer sufocar crises (...) a crise vem por bem ou por mal”. A solução, porém, é simples: "Acolha a crise e pergunte lá dentro o que tenho de aprender, no que posso me desenvolver ou quem pode me ajudar". Entre as pessoas que podem ajudar, está a equipe do profissional: "Quando a pessoa não encontra saída, é a mente engessada, que não está com estratégias disponíveis. Num processo de coaching, a pessoa é estimulada a criar, a pensar novas possibilidades, a buscar suporte, a desenvolver habilidades e competências para alcalçar resultados". O método empregado é a PNL. Perguntas simples, como "O que está faltando para você ser plenamente feliz" e "Se você tivesse seis meses de vida, o que faria?”, são os caminhos para decifrar o que há por trás da crise. Quanto ao método: "É o estudo do modelo do funcionamento da mente humana e como nós podemos intervir neste funcionamento com técnicas eficientes. É preciso cuidar do que está por baixo da resistência, para a estrutura que mantém a pessoa presa ao padrão. Se é um padrão repetitivo, tem estrutura; se é estrutura pode ser reestruturada".

Fundamentos: Há uma perspectiva evolucionista no programa, no sentido de que os indivíduos que conseguem os melhores resultados são os que se adaptam melhor aos desafios pessoais, relacionais e ambientais. "É uma das leis fundamentais da vida: a evolução constante. Está tudo em evolução: as espécies estão em evolução, o universo está em evolução, os planetas estão em evolução, nós estamos em evolução - não adianta querer barrar este processo". Tudo seria, portanto, uma questão de adaptação evolução. "Se você 
está com um problema e não consegue solução, você não está ainda adaptado a ele. É preciso evoluir para se adaptar para este desafio - é a vida te empurrando para a evolução. Evolui, se adapta, aí agora não é mais um problema. Eu desenvolvi musculatura para lidar com este desafio". Há, contudo, a percepção de que se trata de um processo: "ali na frente vem outra crise. É preciso cuidar da vida, nosso maior bem”. O programa também apresenta uma perspectiva otimista em relação aos aparatos técnicos de comunicação: "temos sorte de estarmos vivendo nesta época. A informação está cada vez mais disponível (...). Temos cada vez mais possibilidade de acessar o conhecimento disponível e usar a nosso favor". Finalmente, pode-se dizer que há uma abordagem científica, no sentido de que há uma preocupação de separar os conhecimentos "cientificamente validados" dos saberes tradicionais: "Quer conhecer o conhecimento direcionado para a evolução humana? Vem conhecer a PNL, conhecimentos de ponta, autoaplicáveis e aplicáveis em terceiros - para quem quer usar profissionalmente com outras pessoas - (...) quer sair da autoajuda no sentido de (...) livros mais superficiais? Vem conhecer o conhecimento técnico mais aprofundado". (...)

Inserções comerciais: os produtos são divulgados pelo próprio comunicador, ao longo do programa, em particular ao final, como os atendimentos individuais (proposta de seis sessões), os cursos de introdução à PNL, com o fornecimento do telefone e site para contato.

Interação: não há participação do ouvinte no programa. Os ouvintes são convidados a conhecer os produtos da empresa: "Venha sair deste processo de resistência. A primeira sessão tem $50 \%$ de desconto".

\subsubsection{Caminho Profundo (23'08): regressão e hipnose}

O programa do administrador de empresas Edicélio Bispo, veiculado no dia 25 de junho, foi uma breve aula expositiva sobre a proposta do profissional para tratar algumas doenças com alta incidência contemporânea, como o estresse, a ansiedade, o pânico e a depressão.

Fundamentos: A visão do comunicador é alicerçada nas neurociências, isto é, na perspectiva de que o cérebro regula a percepção da realidade, de forma que técnicas como a regressão e a hipnose poderiam reparar eventuais mapas e atalhos neuronais defeituosos. Ele enfatiza, portanto, "o valor biológico da vida, a garantia da própria vida independente de qualquer coisa. É tão você, é você de verdade. O objetivo é (voltar) a viver e pronto". 
O programa apresenta um forte discurso científico amparado em leituras do comunicador: "Sem se afastar do ponto de vista científico um milímetro de como o sistema nervoso de qualquer ser vivo garante a excelência de viver. São anos de estudos e pesquisas nesta direção." Esta proposta é evolutiva, no sentido de que se manifesta o esforço do profissional no sentido de incorporar ao seu método as novas descobertas científicas: "(O programa se) mantém sempre atualizado, tudo o que se descobre de como a mente funciona se incorpora natural e espontaneamente, técnicas e habilidades são incluídas”.

A dicotomia entre ciência e fé é expressa abertamente: “(...) você não precisa acreditar nem desacreditar. A fé é vista e percebida numa amplitude maior do que seu cérebro funciona. É aquilo que é absoluto. E a função de nosso cérebro é construir o tempo todo mecanismos racionais sobre tudo. (...) Tentando explicar tudo e se posicionar em relação ao outro (...)".

Inserções comerciais: Ao redor da metade do programa (10 minutos) e próximo ao fim (19 minutos) um locutor apresenta a vinheta ("Caminho Profundo: o cérebro emocional em terapia. O estresse, a ansiedade, o pânico e a depressão sem psicanálise nem medicamentos. Converse hoje com o Dr. Bispo e descubra tudo o que a regressão e a hipnose podem fazer por você”). Informa a seguir o e-mail. Segue uma síntese do programa (A Nova Terapia da Mente sem Psicanálise nem Medicamentos) e o telefone de contato.

Interação: não há participação do ouvinte no programa. De toda forma, o ambiente íntimo do meio rádio é enfatizado pelo uso do vocativo, isto é, a fala do comunicador é sempre dirigida diretamente ao ouvinte: "Os seus mapas, a sua realidade, a realidade concreta que você vai viver se aproxima cada vez mais da realidade concreta fora de você. Enfim, é você e você de verdade. (...)". Há, então, o convite a conhecer o método: "Tudo (...) passa pelos caminhos e pelos atalhos de algumas fés absolutas que foram construídas em seu sistema nervoso e que fazem o que acreditam que deve ser feito. Você liga e experimenta no 5041-8000”.

\subsubsection{Falando com o Doutor (21'05): saúde bucal}

O programa é temático. $\mathrm{O}$ do dia 26 de junho é sobre cistos odontogênicos, processo inflamatório crônico causado pela morte da polpa do dente, que pode destruir a estrutura óssea vizinha e desencadear sinusites, parestesias e outras doenças.

Fundamentos: odontologia tradicional.

Inserções comerciais: são relacionadas a partir da resposta do ouvinte, se necessário recomendando a procura de ajuda especializada, em geral da clínica própria. 
Interação: o programa já abre com o odontólogo informando o número das linhas telefônicas, convidando os ouvintes a ligar para tirar dúvidas a respeito do tema do dia. A partir da ligação, ele traça um diagnóstico sobre o caso de forma didática, não raro finalizando com a prescrição de procurar a clínica Paglia. No dia do programa analisado, houve uma ligação de uma ouvinte brasileira da França, que acompanha o programa pela internet. "Eu estou sempre conectada, sempre que possível ouço seu programa".

\subsubsection{O Encontro (23’20): constelação familiar e tarô}

O programa não apresenta uma temática definida a priori e pode ser considerado como um bate-papo entre os dois apresentadores. Ao redor do sétimo minuto do programa, da conversa de Luiz Mota e Simone Arrojo emerge uma espécie de síntese do dia: o sentido da vida.

Fundamentos: Não é possível detectar uma fundamentação teórica propriamente dita. Contudo, nas entrelinhas, é possível notar uma visão que transcende os limites da ciência positivista. Nos anos 1990, este tipo de programa poderia ser catalogado como holístico, no sentido que mescla diferentes tradições, sem se apoiar de forma única ou dogmática em nenhuma delas. De toda forma, pode-se dizer que há uma atitude fenomenológica diante da vida, que pode ser expressa no relato que Simone Arrojo narra: um dia ela estava caminhando na rua e se perguntou sobre estas pessoas que não trabalham, não produzem, não fazem nada, qual o sentido da vida delas. "Aí me veio uma resposta: esta pessoa é tão importante quanto o presidente da República, quanto uma pessoa que se mata para trabalhar, porque a vida é um estar!". Segundo ela, daí lhe "veio uma resposta (...) me veio a noção de uma pedra. Quantos milhares de anos a pedra fica ali naquele estar (...), de simplesmente viver".

Inserções comerciais: Ao redor do décimo minuto, começa-se a falar do tarô, que é o carro-chefe do comunicador Luiz Mota. Aos poucos, a conversa se concentra de forma aparentemente não planejada ao redor da carta 16, a Torre, "que tem a ver com a evolução do homem, que quando chega a 16 ele tomba". Mais próximo do término, o foco fixa-se na constelação familiar, área de Simone Arrojo, com a divulgação das constelações em grupo e da organização da vinda ao Brasil do idealizador da técnica, Bert Hellinger, 87, nos dias 26, 27 e 28 de julho de 2013.

Interação: neste programa em particular, não há convite expresso para participação ao vivo, pois o(s) apresentador(es) estava(m) acompanhando um grupo no Peru. Aliás, as excursões são um produto derivado com provável crescente aceitação pelos ouvintes, haja 
vista a quantidade de comunicadores que estão oferecendo diferentes roteiros. No caso deste programa em particular, o ouvinte fica na posição do voyer, que acompanha o diálogo dos dois comunicadores. A estratégia, contudo, funciona bem, uma vez que há muita empatia entre os dois, o que gera um bate-papo animado e interessante entre eles.

\subsubsection{Seja Sol (24'35): empreendedorismo consciente}

No programa analisado, o apresentador discorreu a respeito da importância do sentimento de gratidão em relação aos acontecimentos e relacionamentos. Eles podem transformar a vida do indivíduo ao atrair fatos positivos. "O sentimento de gratidão coloca sua mente, sua energia, no ter, nas coisas que você quer. Já com o sentimento de insatisfação, a mente fica presa em um não ter constante, pois está sempre prestando atenção no que não se tem - por isso fica-se ingrato e insatisfeito".

Fundamentos: No programa analisado a Lei da Atração pode transformar a vida numa benção, numa mágica, pois se atrai para a realidade aquilo que se sente. Pensar, sentir e agir: o mais importante é o que o indivíduo sente.

Inserções comerciais: o programa é patrocinado pela empresa do apresentador, Brasil Sol Empreendimentos Sustentáveis Ltda. Ao longo dele, Stélio Sol discorre sobre os cursos (como O Jogo da Atração, com ferramentas para acelerar o processo de atração consciente de coisas que se deseja alcançar, como sonhos e projetos - R $\$ 30$ por pessoa) e, sobretudo, a venda de lotes na Ecovila Caminho de Abrolhos (terrenos de $450 \mathrm{~m}^{2}$ a partir de R\$ 25 mil) localizado no sul da Bahia. Esta é anunciada nos cinco minutos finais do programa.

Interação: não há participação do ouvinte no programa. De toda forma, o ambiente do meio rádio é enfatizado a partir do uso do vocativo, isto é, a fala do comunicador é sempre dirigida diretamente ao ouvinte. "(Ligue agora para...”).

\subsubsection{Mundial e Você (54'05): uma vitrine da "família Mundial"}

Neste programa, a jornalista Samira Chahine entrevista comunicadores da própria rádio Mundial. A entrevistada do dia é Kátia Rigotti, comunicadora do programa Despertar, realizado das $15 \mathrm{~h}$ às $15 \mathrm{~h} 30$ às quartas-feiras. Formada na área da saúde pela Faculdade do Hospital Israelita Albert Einstein, com MBA em Educação, Empreendedorismo e Inovação pela FGV, a comunicadora é especialista em Aférese Terapêutica (terapia realizada com a finalidade de remover uma substância anormal, ou presente em excesso na circulação, no tratamento de uma determinada doença) pelo WAA-World Apheresis Association. Médium 
e sacerdotisa na cultura afro-brasileira, ela emprega várias técnicas, como os cristais de $\mathrm{Oz}$, para tratar de diversas doenças.

Fundamentos: do ponto de vista das ciências da comunicação, a jornalista Samira Chahine emprega técnicas da entrevista aprofundada, numa abordagem compreensiva, para mergulhar na história de vida do entrevistado.

Inserções comerciais: o programa é dividido em dois blocos, de aproximadamente 27 minutos cada. Entre eles há apenas a vinheta da Rádio Mundial.

Interação: não há interação com o ouvinte. Ocorre, antes, um diálogo profundo entre entrevistado e entrevistador num clima compreensivo (KÜNSCH, 2008) e sem julgamentos ou juízos de valor. Não há certo ou errado, antes ocorre uma tentativa de compreender o outro. Do lado do entrevistador, há um evidente conhecimento sobre este campo do entrevistado, que mescla diversas visões de mundo e possibilidades de tratamento. Nota-se igualmente um excelente preparo prévio da entrevistadora sobre o trabalho do entrevistado, que resulta no "diálogo possível" conforme proposto pela pesquisadora brasileira de comunicação Cremilda Medina (1990). Do lado do entrevistado, pelo menos no dia do programa analisado, notou-se a percepção deste campo fértil para o diálogo, o que resultou numa abertura real para expor de forma aprofundada a visão e a experiência da profissional a respeito do conteúdo abordado.

\section{CONSIDERAÇÕES}

A audição atenta dos programas, em perspectiva fenomenológica, indica a relevância dos mesmos e da emissora para compreensão dos processos de comunicação e cultura no Brasil contemporâneo. Assim, como este texto relata parte de uma pesquisa em andamento, apontamos alguns elementos que poderão ser aprofundados no desenvolvimento das investigações.

Coexiste, na ação dos locutores e na participação dos ouvintes, a tensão entre um processo de comunicação na perspectiva linear - alguém fala para persuadir o outro - e o processo de comunicação em perspectiva sistêmica, isto é, quando de alguma maneira a comunicação acontece entre protagonistas envolvidos, de uma forma orquestral, imprevisível. Os locutores falam considerando o rádio como meio para convencimento dos ouvintes e, provavelmente, o estudo deste processo será mais fecundo se considerarmos, como já dizia o antropólogo norte-americano Ray Birdwhistell (1918-1994), que o indivíduo não se comunica, ele participa de uma comunicação ou se torna elemento dela. Em outras palavras, "ele não é autor da comunicação, ele participa dela" (Birdwhistell apud 
WINKIN, 1998, p. 81). Esta perspectiva poderá ser aprofundada através de autores como os vinculados à Escola de Palo Alto, estudiosos que investigaram uma perspectiva orquestral da comunicação para questionar as antigas teorias funcionalistas (estímulo/resposta).

Outro caminho a ser percorrido na compreensão dos processos comunicativos ao redor da emissora de rádio pode ser o estudo dos espaços criados pelos diferentes tipos de capilaridades da comunicação, isto é, pelos tipos de ambientes cultivados pela comunicação. Tais ambientes são caracterizados pela comunicação presencial que ocorre nos estúdios e nos ambientes de audição (capilaridade presencial), pela forma como as mensagens são também lidas a partir de um acervo de narrativas transcritas em livros (capilaridade alfabética), pelos sinais codificados e decodificados eletronicamente de forma instantânea (capilaridade elétrica) e também pelos sinais disponíveis na internet e acessíveis como se fossem, nas palavras de Norval Baitello Jr., o vento que "penetra por todas as frestas e buracos permanentemente" (capilaridade eólica) (BAITELLO, 2010, p. 113). Neste quesito da capilaridade eólica, ressalta-se que em um dos programas analisados, uma brasileira que reside no hemisfério norte tirava dúvidas sobre sua saúde bucal, ao mesmo tempo em que se nutria emocionalmente dos sons da pátria e do idioma português por meio do programa radiofônico acessado pela internet.

O estudo das narrativas que constituem o acervo simbólico, a noosfera que o homem cultiva para dar algum sentido à sua luta cotidiana, também se mostra fecundo na audição da programação da emissora. Narrativas expressas também em imagens endógenas que constituem o universo do imaginário que pode ser investigado a partir de pesquisadores como Gilbert Durand (2012), Edgar Morin (1979), Malena Contrera (2010), Monica Martinez (2008) e Edilson Cazeloto (2012).

Há que se observar, igualmente, que no campo jornalístico este estudo se insere na perspectiva do Jornalismo Literário (LIMA, 2009), enquanto uma modalidade ampliada e compreensiva do jornalismo, que emprega recursos das Ciências Sociais Aplicadas e de outras áreas do conhecimento, como a Psicologia e a Sociologia, entre outras, para captar a realidade de forma mais acurada e, assim, poder relatá-la com profundidade - o que na mídia escrita em geral é feito por meio do emprego de técnicas advindas da literatura.

Outro caminho para compreensão da participação dos protagonistas no processo de comunicação da emissora pode ser encontrado nas noções da chamada cultura do ouvir, especialmente na possibilidade de se investigar a capacidade de vibração dos corpos diante das sonoridades de outros corpos, de se compreender o ambiente comunicacional da 
emissora como espaço de participação nos quais os corpos dos protagonistas que falam ou ouvem são tocados pelas ondas de outros corpos (MENEZES, 2012a, p. 33).

Finalmente, os processos de comunicação que enredam os corpos dos protagonistas antes e depois dos aparatos eletrônicos não se limitam ao uso de aparelhos de conexão em AM, FM ou através da internet. Os protagonistas (locutores ou ouvintes) de alguma forma estão vinculados, estão articulados por elos simbólicos ou materiais cultivados em espaços comuns que podem ser estudados como uma possível ecologia da comunicação. De alguma maneira, como lembramos no início deste texto, o processo de comunicação/cultura se esparrama pelas porosidades entre os corpos e universos simbólicos dos protagonistas ouvintes e locutores - embalados na experiência sonora da emissora.

\section{REFERÊNCIAS}

BAITELLO Jr., Norval. As capilaridades da comunicação. In: BAITELLO Jr., Norval. A serpente, a maça e o holograma. Esboços para uma Teoria da Mídia. São Paulo: Paulus, 2010. Págs. 103-113.

BRECHT, Eugen Bertold Friedrich. Teoria do Rádio (1927-1932). In: MEDITSCH, Eduardo. Teorias do Rádio. Textos e contextos. Vol. 1. Florianópolis: Insular, 2005. Págs. 35- 45.

CAZELOTO, Edilson. Hipóteses para a pesquisa do imaginário na cibercultura. In: COELHO, Cláudio. N. P.; KÜNSCH, Dimas A.; MENEZES, J. Eugenio (Orgs.). Estudos de comunicação contemporânea. Perspectivas e trajetórias. São Paulo: Pleiade: 2012. Págs. 123-139. Disponível em: < http://www.casperlibero.edu.br/noticias/index.php/1969/12/31/livros,n=9233.html >. Acesso em: 25 jun. 2013.

CONTRERA, Malena. Mediosfera. Meios, imaginário e desencantamento do mundo. São Paulo: Annablume, 2010.

DURAND, Gilbert. As Estruturas Antropológicas do Imaginário. São Paulo: WMF Martins Fontes, 2012.

KÜNSCH, Dimas A. Teoria Compreensiva da Comunição. In: KÜNSCH, Dimas A.; BARROS, Laan Mendes de (Orgs.). Comunicação. Saber, Arte ou Ciência: questões de teoria e epistemologia. São Paulo: Plêiade, 2008. Págs. 173-195.

LIMA, Edvaldo Pereira. Páginas Ampliadas: o livro-reportagem como extensão do jornalismo e da literatura. $4^{\text {a }}$. edição. São Paulo: Manole, 2009.

MARTINEZ, Monica. Jornada do Herói: estrutura narrativa mítica na construção de histórias de vida em jornalismo. São Paulo: Annablume/Fapesp, 2008.

MEDINA, Cremilda de Araújo. Entrevista: o diálogo possível. São Paulo: Ática, 1990. 
MENEZES, José Eugenio de O. Rádio informativo e ecologia da comunicação: o Jornal da CBN como cenário de vinculação sociocultural. In: MARQUES, Angela et alli (Orgs.).

Esfera Pública, Redes e Jornalismo. Rio de Janeiro: E-Papers, 2009. Págs. 273-285.

MENEZES, J.E.O.; MARTINEZ, M. Jornalismo e tempo profundo: o trabalho de Nelson Araújo no Globo Rural. In: SILVA, Gislene; KÜNCH, Dimas et al. (Orgs.). Jornalismo Contemporâneo. Figurações, impasses e perspectivas. Salvador: EDUFBA/Compós, 2011.

MENEZES, José Eugenio de O. Vínculos sonoros e ecologia da comunicação. In:

BORNHAUSEN, Diogo A.; MIKLOS, Jorge; SILVA, Maurício Ribeiro da. (Orgs.).CISC - 20 anos. Comunicação, cultura e mídia. São José do Rio Preto: Bluecom, 2012. Págs. 445-458. Disponível em: 〈www.cisc.org.br〉. Acesso em: 30 jun. 2013.

MENEZES, José Eugenio de O.; CARDOSO, Marcelo. (Orgs.). Comunicação e Cultura do Ouvir. São Paulo: Plêiade, 2012a. Disponível em: < http://www.casperlibero.edu.br/noticias/index.php/,n=9096.html>. Acesso em: 30 jun. 2013.

MORIN, Edgar. O enigma do homem. Para uma nova antropologia. Rio de Janeiro: Zahar, 1979.

RÁDIO MUNDIAL. Histórico. Disponível em: < http://radiomundial.com.br/historico $>$. Acesso em: 30 jun. 2013.

WINKIN, Yves. A nova comunicação. Da teoria ao trabalho de campo. Campinas: Papirus, 1998.

Original recebido em: 15/08/2013

Aceito para publicação em: Novembro de 2013

José Eugenio de Oliveira Menezes

Doutor em Ciências da Comunicação pela ECA-USP, é docente do Programa de PósGraduação em Comunicação da Faculdade Cásper Líbero (São Paulo - SP).

Monica Martinez

Doutora em Ciências da Comunicação pela ECA-USP, tem pós-doutorado pela Umesp e é docente do Programa de Pós-Graduação em Comunicação e Cultura da Uniso (Sorocaba- 